\title{
O USO DO PLANEJAMENTO ESTRATÉGICO SITUACIONAL (PES) EM UNIVERSIDADES PÚBLICAS: O CASO DA PRÓ-REITORIA DE AVALIAÇÃO E PLANEJAMENTO DA UNIVERSIDADE FEDERAL DO TOCANTINS.
}

\author{
Waldecy Rodrigues ${ }^{1}$ \\ Michele Trombini Duarte ${ }^{2}$ \\ Airton Cardoso Cançado ${ }^{3}$
}

\section{Resumo}

Este artigo apresenta a aplicação da metodologia do Planejamento Estratégico Situacional (PES) na Pró Reitoria de Avaliação e Planejamento (PROAP), e os primeiros resultados deste processo. Entende-se que é necessário ressaltar que este planejamento deve ser dinâmico, e de um modo geral adaptar-se a dinâmica do ambiente interno e externo, e de modo especial à dinâmica das pessoas. Por este motivo tão importante quanto a realização do planejamento é seu monitoramento a fim de promover ajustes que aumentem a capacidade de realizar sua visão de futuro.

Palavras-chave Planejamento estratégico. Universidade Federal. Administração Pública.

\begin{abstract}
This paper sought to present the situational strategic planning process, and the first results PROAP / UFT this process means that it is necessary to emphasize that this planning should be dynamic, and generally adapt to the dynamics of the internal and external environment, and particularly the dynamics of the people. For this reason as important as achievement of strategic planning is monitoring in order to promote adjustments that enhance the ability to carry out his vision of the future.
\end{abstract}

Keywords: Strategic planning. Federal University. Public Administration.

\footnotetext{
${ }^{1}$ Pós- doutor em Economia. Doutor em estudo de desenvolvimento comparado. Professor associado. Programa de pós-graduação em Desenvolvimento Regional. Universidade Federal do Tocantins (UFT). Email: waldecy@terra.com.br]

${ }^{2}$ Mestre em gestão de políticas pública (UFT) Email: msduarte@uft.edu.br

${ }^{3}$ Doutor em Administração. Professor adjunto. Programa de pós-graduação em Desenvolvimento Regional. Universidade Federal do Tocantins (UFT). Email:airtoncardoso@ yahoo.com.br
}

Revista de Administração Educacional, Recife, V. 1 . No 1 . 2017 jan./jun. 2017 p. -38- 


\section{INTRODUÇÃO}

As organizações têm como principal característica seu caráter sistêmico, onde todas as partes buscam conjuntamente a realização de um objetivo. As Universidades Federais, assim como qualquer outra instituição, existem para viabilizar determinadas ações decorrentes da sua missão. Entretanto, por serem organizações complexas, de responsabilidade pública, a realização destas ações torna-se cada vez mais desafiadora, tendo em vista a escassez de recursos; a multiplicidade de serviços; a elevada estrutura de gastos fixos e, um complexo ambiental institucional.

As Universidades possuem características que a configuram como uma estrutura de muitas complexidades, assim: os profissionais demandam autonomia no trabalho e liberdade de supervisão; as decisões são descentralizadas; coexistem concepções distintas de universidade, o poder é ambíguo e disperso; a universidade tem metas ambíguas e vagas (ARAÚJO, 1996). E isto pode causar problemas de diversas naturezas, principalmente aqueles que exigem controle, direção e avaliação.

Para enfrentar os desafios propostos a gestão universitária, alguns administradores têm começado a usar diversas metodologias de administração e gestão para poder identificar as forças e tendências do ambiente. Os métodos tradicionais de planejamento tornaram-se inadequados para acompanhar um sistema tão complexo. Pois, são necessários instrumentos que motive aspectos desta cultura organizacional, que se caracteriza por ter uma hierarquia pouco rígida, e diversos interesses heterogêneos em uma mesma organização.

Neste contexto surge a utilização de metodologias participativas de gestão e organização, tais como o Planejamento Estratégico Situacional (PES) no qual o planejamento é precedido e acompanhado por uma análise ambiental, não sendo o futuro projetado simplesmente pelos eventos passados e de forma passiva. No PES os atores têm uma voz e atuação participativa, na definição dos planos de ação e de sua execução.

Neste artigo é descrita a aplicação da metodologia do Planejamento Estratégico Situacional (PES) na Pró Reitoria de Avaliação e Planejamento, demonstrando os passos seguidos e os resultados iniciais de implementação obtidos.

Revista de Administração Educacional, Recife, V. 1 . № 1 . 2017 jan./jun. 2017 p. -38- 


\section{A DIFICULDADE DE SE FAZER PLANEJAMENTO EM UNIVERSIDADES}

No Brasil, embora existam universidades que estejam por iniciar ou na tentativa de implementar o processo de planejamento visualiza-se que, o planejamento constante, científico e sistematizado não tem sido uma prática das universidades até anos bem recentes e quando existe o processo de planejamento é algo setorial ou limitado a produzir um plano de ação.

As Universidades Públicas vista como organizações, apresentam estruturas que exigem a definição de práticas de gestão que busquem resultados demandados pela sua comunidade interna e externa. Este processo, no entanto, nem sempre é racional, ordenado ou orientado para soluções pragmáticas dos problemas. Podendo ser orientados para atender pressões institucionais e de eficiência, essas variações nos padrões de resposta resultam das características peculiares da universidade vista como organização (LOPES,1999).

Alpertedt, Martignago, Fiates (2006) reafirmam este pensamento de Lopes (1999) para os autores, nas universidades a implantação das mudanças condiciona-se à sua legitimação junto aos seus agentes da Instituição, revelando o caráter complexo e incerto deste ambiente organizacional. A adoção de formas mais flexíveis por parte da universidade, gerou uma maior possibilidade de participação de todas as partes envolvidas, porém, originou uma organização extremamente complexa, tornando muito complicadas as linhas de hierarquia e de responsabilidade dentro da organização.

O planejamento estratégico em sua forma tradicional tende a não gerar resultados eficazes em organizações complexas como são as universidades, pelo fato de sua complexidade, níveis hierárquicos pouco rígidos e necessidade de formas de controle e avaliação adaptativas a este ambiente. Embora não se possa desconsiderar que os gestores tenham a preocupação com a maximização dos resultados, é pouco provável que eles tenham uma postura orientada somente pela dimensão racional do ser humano. Neste sentido, a perspectiva metodológica ofertada pelo Planejamento Estratégico Situacional (PES) pode ser mais adequado, pois envolve os atores institucionais desde o seu nascedouro, promovendo o sentimento de pertencimento na organização e responsabilização substantiva no desenvolvimento das ações e nos seus processos avaliativos.

\section{O PLANEJAMENTO ESTRATÉGICO SITUACIONAL - PES}

O Planejamento Estratégico Situacional (PES) foi sistematizado pelo economista chileno Carlos Matus e é concebido sobre o pilar da gestão de governo da arte de governar, é

Revista de Administração Educacional, Recife, V. 1 . № 1 . 2017 jan./jun. 2017 p. -38- 
um processo dinâmico que pressupõe constante adaptação a cada situação concreta onde é efetuada a sua aplicação.

O PES segundo Matus (1993), apresenta três características que o definem. A primeira é o subjetivismo, que tem por objetivo identificar e analisar uma situação problemática, centra-se na diversidade das percepções dos indivíduos envolvidos. É necessário, portanto, diferenciar as percepções e as formas distintas que os diversos autores participam do jogo social, sem ignorar nenhuma, para que a realidade não seja explicada simplesmente por um diagnóstico, mas, pelas diferentes interpretações dos agentes envolvidos e, de seus diferentes propósitos. A segunda é a elaboração de planos, criados em função da diferença entre a realidade atual do jogo social e as aspirações de um ator de acordo com seu mundo subjetivo. A última característica aponta a dificuldade de predição do futuro, desta forma esta metodologia busca enumerar possibilidades e preparar os atores para enfrentá-las.

O PES é uma metodologia que envolve diversos atores com diversos interesses e motivações além dos tradicionalmente ligados ao processo de planejamento, fazendo com que se contraponha ao planejamento tradicional. A forma dialógica e situacional na discussão dos problemas, na identificação de cenários, na proposição de alternativas para as soluções (mesmo que temporárias) colocam o PES como uma boa opção de planejamento para instituições complexas como são as universidades públicas. Além disso, tem a variável política presente na elaboração da viabilidade e da vulnerabilidade do plano.

\section{MATERIAL E MÉTODOS}

No PES, a participação de todos os atores é considerada elemento essencial para a implantação das estratégias, pois eles apresentam valores, visões, propósitos e ideias diferentes uns dos outros, o que contribui para a efetividade das ações propostas. $\mathrm{Na}$ concepção de Matus (1993) o planejamento é composto por quatro etapas principais: estabelecimento dos objetivos a alcançar, tomada de decisões a respeito das ações futuras, elaboração de planos e ação.

Assim, Matus (1993) disserta sobre planejamento como este sendo o cálculo que precede e preside a ação em qualquer espaço do jogo social e que, portanto, tem a intenção de aumentar a capacidade de governo do ator, isto é, aumentar a perícia pessoal que envolve capital intelectual e capital de experiência de articulação política. O plano é, nesse raciocínio, uma aposta política com fundamento técnico.

Discorrendo sobre estratégia, Matus (1991) escreve que "o cálculo estratégico se

Revista de Administração Educacional, Recife, V. 1 . No 1 . 2017 jan./jun. 2017 p. -38- 
refere a pensar estratégias para tornar o plano viável", realizando uma crítica ao planejamento normativo ao destacar que, neste, a parcela econômica é tratada de modo determinístico e no plano prescritivo. O pensamento estratégico então na visão de Matus leva a uma análise integral da realidade, sem separar o econômico do político.

De tal forma Matus (1993), toma como proposta conceitual e metodológica a noção de situação, entendida como um conjunto de problemas identificados, descritos e analisados na perspectiva de determinado ator social. Problema é algo considerado fora dos padrões de normalidade do ponto de vista de um ator social. Esses padrões são definidos a partir do conhecimento, do envolvimento do ator com o problema, da capacidade de agir do ator sobre determinada situação.

Portanto, pode-se perceber que o planejamento tem sua gênese na delimitação dos objetivos e, por conseguinte, o detalhamento dos planos para os atingirem de maneira tangível. Assim, fica subentendido que planejar é definir os objetivos e escolher antecipadamente o melhor curso de ação para alcançá-los, ou seja, pensar antes de se executar. O planejamento define onde se pretende chegar, o que deve ser feito, quando, como e em que sequência.

A proposta geral da metodologia de Matus (1992) se fundamenta num arcabouço teórico que enfatiza o conceito de situação e contempla um conjunto de métodos a serem utilizados nos diversos momentos do processo de planejamento, quais sejam, o "explicativo", o "normativo", o "estratégico" e o "tático-operacional".

O momento explicativo, que equivale ao diagnóstico da planificação normativa, entende que a realidade é explicada mediante a seleção de problemas relevantes, buscando a compreensão mais ampla da razão de tais problemas ocorrerem. (MATUS, 1992, p. 125)

O momento normativo segundo o autor, fornece o desenho do que deve ser; é a definição de como deve ser a realidade. É diferente do momento explicativo, que se move no plano de "como é ou como tende a ser a realidade". O momento normativo é o aspecto central de toda planificação. (MATUS, 1992, p. 132),

O momento estratégico busca responder quais operações/ações do plano são viáveis ou inviáveis, quais possíveis reações cada ator envolvido no problema terá e como construir a viabilidade para as ações inviáveis. O problema da viabilidade é muito importante no momento estratégico. (MATUS, 1992, p. 137)

Momento tático-operacional de implementação das ações propostas. É necessário fazer a mediação do plano na realidade, isto é, adequá-lo diante das situações que se apresentam no

Revista de Administração Educacional, Recife, V. 1 . № 1 . 2017 jan./jun. 2017 p. -38- 
cotidiano de colocar em prática tudo o que foi planificado. Nesta fase, é preciso verificar se o plano se adapta ao cenário, ao tempo e às condições do que foi proposto. (MATUS, 1992, p. 142)

A metodologia para a elaboração do Plano Estratégico Situacional da PROAP foi desenvolvida baseados nos princípios de Matus (1991, 1992, 1993) e no trabalho de Marcelino (2001).

Operacionalmente, a metodologia foi desenvolvida divididos em três momentos distintos:

a) No primeiro momento, os participantes utilizaram a técnica de "Brain-writing", trabalhando, individualmente, com formulários previamente estruturados, gerando ideias por escrito; é uma técnica de grupo nominal, sem possibilidade de interação verbal para que não se iniba a geração de ideias;

b) No segundo momento, o grupo nominal se transformou em grupo de trabalho no qual as ideias são discutidas em busca do consenso do grupo, utilizando as técnicas tradicionais de dinâmica de grupo;

c) O terceiro momento aconteceu no grande grupo (plenária), através do debate e consenso sobre o tema, tendo como base as contribuições dos pequenos grupos.

O processo de formulação do Plano Estratégico para a PROAP foi desenvolvido através das seguintes etapas:

1. Cenários prospectivos do futuro;

2. Definição da Missão Institucional da PROAP;

3. Análise Ambiental Externa: Ameaças e Oportunidades;

4. Análise Ambiental Interna: Pontos Fortes e Pontos Fracos;

5. Definição dos Objetivos Estratégicos;

6. Estratégias e Visão do Futuro - o Cenário Planejado;

7. Elaboração de Programas e Projetos;

8. Plano de Implantação.

O processo foi desenvolvido por meio de reuniões com a participação de toda a equipe da Pró Reitoria (Pró-reitor, Diretores, servidores, estagiários e terceirizados). Segundo o autor "o principal benefício do planejamento participativo não é seu produto, ou seja, o plano, mas o processo envolvido" (MARCELINO; 2001, p. 08)

Todos os servidores da Pró Reitoria foram ouvidos e pode apresentar sua percepção sobre as dificuldades enfrentadas pelas Diretorias e, com isso pode-se refletir sobre uma série

Revista de Administração Educacional, Recife, V. 1 . No 1 . 2017 jan./jun. 2017 p. -38- 
de questões fundamentais para a determinação do futuro desejado de cada Diretoria em termos de oportunidades e ameaças e uma análise do ambiente interno em termos de pontos fortes e pontos fracos, com esta analise pode-se definir a missão de cada Unidade e através destas definir a missão da Pró Reitoria .

No processo de Planejamento estratégico tem se utilizado diversas ferramentas e métodos para auxiliar as instituições, dentre eles está a matriz SWOT. Esta matriz desenvolvida nas escolas americanas de administração, cuja sigla significa: Strenghts (forças), Weakness (fraquezas), Opportunities (oportunidades) e Treats (ameaças), objetiva definir estratégias para manter pontos fortes, reduzir a intensidade dos pontos fracos, aproveitando as oportunidades bem como, proteger das ameaças.

A análise da Matriz SWOT é uma ferramenta essencial para uma organização, pois ela permite obter uma visão clara e objetiva sobre quais são suas forças e fraquezas no ambiente interno e suas oportunidades e ameaças no ambiente externo e a partir desta analise pode-se construir estratégias para melhorar o desempenho organizacional. A função da análise SWOT é compreender fatores influenciadores e apresentar como eles podem afetar a iniciativa organizacional, levando em consideração as quatro variáveis citadas (forças, fraquezas, oportunidades e ameaças), com base nas informações obtidas instituição poderá melhor conhecer seus desafios e elaborar seus objetivos a partir destes.

Após a análise do ambiente, evidenciando o conjunto de deficiências mais importantes foi -se em busca da identificação dos problemas, a tarefa dos participantes foi refletir e a partir do seu próprio ângulo de visão, sobre as causas dos problemas;

Uma das variáveis mais importantes do planejamento estratégico é atenção aos ambientes interno e externo, nas Universidades revela-se um espaço fechado devido ao fato de que elas não são administradas a partir de um modelo voltado ao mercado e, custosbenefícios, porém, as universidades enfrentam ameaças, necessitam competir por recursos, adequar seus programas acadêmicos às demandas da sociedade (Araújo, 1996).

\section{RESULTADOS E DISCUSSÕES}

A Fundação Universidade Federal do Tocantins (UFT), instituída pela Lei n. 10.032, de 23 de outubro de 2000, vinculada ao Ministério da Educação, é uma entidade pública destinada à promoção do ensino, pesquisa e extensão. É dotada de autonomia didático-

Revista de Administração Educacional, Recife, V. 1 . No 1 . 2017 jan./jun. 2017 p. -38- 
científica, administrativa e de gestão financeira e patrimonial, em consonância com a legislação vigente.

Atualmente, é a mais importante instituição pública de ensino superior do Estado, em termos de dimensão e desempenho acadêmico. A Universidade oferece 48 cursos de graduação presenciais, 03 a distância, além de 17 programas de mestrado e 4 de doutorados reconhecidos pela Capes. Também há vários cursos de especialização lato sensu, com aproximadamente 17.000 alunos presenciais.

A estrutura multicampi da UFT está distribuída em 7 (sete) campi universitários e mais 11 (onze) polos de Educação a Distância (EAD), localizados em regiões estratégicas do Estado do Tocantins. Pode, dessa forma, contribuir com o desenvolvimento local e regional, ofertando ensino superior público e gratuito em diversos níveis.

A Reitoria é órgão executivo de administração, coordenação, fiscalização e superintendência das atividades universitárias, composta pelas Pró Reitorias de: Graduação, Pesquisa e Pós-Graduação; Extensão e Assuntos Comunitários Administração e Finanças, Avaliação e Planejamento, Assuntos Estudantis; e Prefeitura Universitária.

A Pró Reitoria de Avaliação Planejamento (PROAP) é a responsável pela concepção e implementação do modelo de Planejamento Estratégico da Universidade. A PROAP da Universidade Federal do Tocantins foi criada em 26 de junho de 2008, partindo de um núcleo denominado Núcleo de Estatística e Planejamento (NEP). Atualmente a Pró Reitoria é constituída por três Diretorias sendo: Planejamento, Gestão Orçamentária e Avaliação.

O organograma apresentado na figura 1 representa a estrutura da Pró- reitoria de Avaliação e Planejamento

Figura 1 - Organograma da PROAP

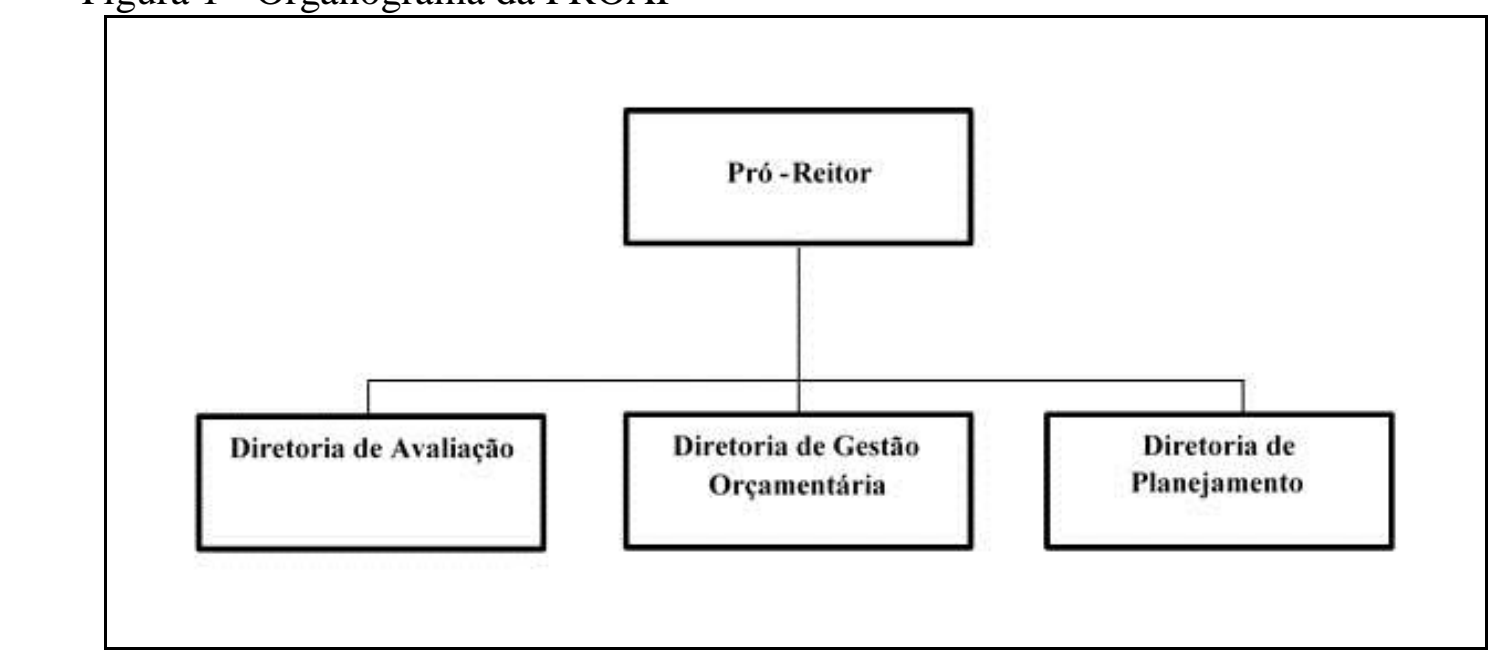

Fonte: Elaboração Própria

Revista de Administração Educacional, Recife, V. 1 . No 1 . 2017 jan./jun. 2017 p. -38- 
O maior nível de planejamento observado na Universidade federal do Tocantins é seu Plano de Desenvolvimento Institucional. Este plano expõe as prioridades institucionais, os eixos e objetivos estratégicos. Contempla, ainda, a apresentação do Projeto Político Institucional - PPI, documento que apresenta as políticas pelas quais são desenvolvidas o ensino, a pesquisa, a extensão universitária, da gestão institucional, das políticas de comunicação e divulgação das Informações da Universidade e Responsabilidade Social. (LIMA, 2015).

No PDI da UFT, a inserção dos atores envolvidos no ambiente institucional (comunidade discente, docentes e técnicos administrativos), sua flexibilidade na formulação de seus objetivos e sua apreciação pelo Conselho Universitário pelos representantes de todos os segmentos da universidade e, assim, o tornando democrático, conotam a ancoragem no Planejamento Estratégico Situacional - PES.

O processo de planejamento da PROAP começou pela necessidade de superar as dificuldades em envolver outros segmentos ou unidades da instituição nas práticas de planejamento, implementação e avaliação das ações. Isso fez com que a própria unidade sentisse a necessidade de conhecer melhor seu ambiente e realizar um planejamento com uma visão mais estratégica.

Os resultados das reuniões realizadas com o propósito de realizar o Planejamento da PROAP, serão apresentados a seguir, de forma resumida e representam o consenso dos participantes.

Na primeira reunião foi formulada e realizada a análise ambiental através da análise SWOT, com a definição das oportunidades e ameaças dos pontos fortes e pontos fracos. $\mathrm{O}$ resultado deste trabalho está apresentado no quadro 1.

Quadro 1 - Identificação dos pontos fortes, fracos e oportunidades e ameaças da PROAP

\begin{tabular}{|c|c|c|c|}
\hline $\begin{array}{c}\text { S } \\
\text { Forças }\end{array}$ & Fraquezas & O & Oportunidades \\
Cooperação da \\
equipe & $\begin{array}{c}\text { Acesso aos serviços } \\
\text { de TI }\end{array}$ & $\begin{array}{c}\text { Disseminação do } \\
\text { Gespública }\end{array}$ & $\begin{array}{c}\text { Crise orçamentária } \\
\text { da universidade }\end{array}$ \\
$\begin{array}{c}\text { Infraestrutura } \\
\text { Bom ambiente de } \\
\text { trabalho }\end{array}$ & $\begin{array}{c}\text { Desmotivação ante } \\
\text { aos problemas da } \\
\text { universidade }\end{array}$ & $\begin{array}{c}\text { Integração com as } \\
\text { outras Pró Reitoria } \\
\text { s da UFT }\end{array}$ & $\begin{array}{c}\text { Conflitos internos } \\
\text { de interesses }\end{array}$ \\
\hline
\end{tabular}

Revista de Administração Educacional, Recife, V. 1 . No 1 . 2017 jan./jun. 2017 p. -38- 


\begin{tabular}{|c|c|c|}
\hline $\begin{array}{l}\text { Qualificação da } \\
\text { equipe } \\
\text { Vários projetos em } \\
\text { andamento }\end{array}$ & $\begin{array}{l}\text { Muito esforço gasto } \\
\text { com questões } \\
\text { operacionais } \\
\text { Falta de } \\
\text { informatização dos } \\
\text { processos }\end{array}$ & $\begin{array}{l}\text { Construção do } \\
\text { Plano de } \\
\text { Desenvolvimento } \\
\text { Institucional }\end{array}$ \\
\hline
\end{tabular}

Fonte: Elaboração própria

Após a identificação dos pontos fortes e fracos, das oportunidades e ameaças, o passo tomado foi a definição da missão de cada uma das três diretorias que compõem o organograma da PROAP e, a partir delas, foi elaborada e validada pelo grupo a missão da Pró Reitoria , como apresenta o quadro 2:

Quadro 2 - Definição dos atributos da PROAP e das Diretorias que compoem sua estrutura organizacional

\begin{tabular}{|c|c|c|}
\hline \multicolumn{3}{|c|}{ MISSÃO } \\
\hline Diretoria de Planejamento & $\begin{array}{l}\text { Diretoria de Gestão } \\
\text { Orçamentária }\end{array}$ & Diretoria de Avaliação \\
\hline $\begin{array}{l}\text { Assessorar a administração } \\
\text { superior nos processos de } \\
\text { planejamento institucional, de } \\
\text { modernização da estrutura } \\
\text { organizacional e de melhoria da } \\
\text { gestão universitária, } \\
\text { proporcionando condições e } \\
\text { ambientes ideais para UFT } \\
\text { buscar a excelência nos âmbitos } \\
\text { administrativos e também de } \\
\text { ensino, pesquisa e extensão. }\end{array}$ & $\begin{array}{l}\text { Assessorar a administração } \\
\text { superior nos processos de } \\
\text { planejamento, gestão e } \\
\text { execução Orçamentária da } \\
\text { Universidade por meio dos } \\
\text { mecanismos de supervisão e } \\
\text { acompanhamento das execuções } \\
\text { das despesas previstas no } \\
\text { orçamento da UFT, visando ao } \\
\text { alcance dos objetivos e metas } \\
\text { institucionais. }\end{array}$ & $\begin{array}{l}\text { Assessorar a administração } \\
\text { superior da UFT nos processos } \\
\text { de monitoramento e promover } \\
\text { avaliação dos resultados } \\
\text { alcançados no desempenho das } \\
\text { atividades da Universidade. }\end{array}$ \\
\hline \multicolumn{3}{|c|}{$\begin{array}{c}\text { Missão da PROAP } \\
\text { Proporcionar condições para que a UFT cumpra as metas definidas no Plano de Desenvolvimento } \\
\text { Institucional. }\end{array}$} \\
\hline \multicolumn{3}{|c|}{$\begin{array}{c}\text { Visão da PROAP } \\
\text { Sua visão é ser reconhecida nacionalmente, até 2022, pela excelência em planejamento, gestão } \\
\text { orçamentária, avaliação e modernização da gestão da Universidade nas áreas administrativa, de ensino, } \\
\text { pesquisa e extensão. }\end{array}$} \\
\hline & $\begin{array}{l}\text { Valores } \\
\text { Ética } \\
\text { Transparência } \\
\text { Respeito aos colaboradores } \\
\text { Credibilidade }\end{array}$ & \\
\hline
\end{tabular}

Fonte: Elaboração própria

Revista de Administração Educacional, Recife, V. 1 . No 1 . 2017 jan./jun. 2017 p. -38- 
Tendo a definição da missão das diretorias e da Pró Reitoria como um todo além da visão e valores, foram definidos os objetivos os quais foram estabelecidos conforme quadro 3 . Quadro 3 - Objetivos da PROAP

\begin{tabular}{|l|}
\hline \multicolumn{1}{|c|}{ OBJETIVOS } \\
\hline Melhorar os processos de Execução Orçamentária na UFT \\
\hline $\begin{array}{l}\text { Construção do Plano de Desenvolvimento Institucional com os elementos necessários } \\
\text { para o monitoramento das ações }\end{array}$ \\
\hline Envolver a todos os servidores da PROAP nas atividades e objetivos institucionais \\
\hline Melhorar a participação no processo de avaliação institucional \\
\hline Criar instrumentos para monitoramento dos resultados da UFT \\
\hline Estabelecer articulação com as demais Pró Reitoria s da UFT. \\
\hline Readequar a estrutura organizacional da Pró Reitoria \\
\hline Promover o aperfeiçoamento profissional continuado \\
\hline Melhoria na Prestação de Contas e na transparência da Universidade \\
\hline Concluir desenho do Novo Modelo de Gestão da Pró Reitoria \\
\hline Buscar mecanismos para a modernização da Gestão \\
\hline
\end{tabular}
Fonte: Elaboração própria

Por último, os participantes, no último encontro definiram as estratégias relevantes a serem desenvolvidas no Plano Estratégico da PROAP para o período 2015-2018, conforme demonstrado no quadro 4.

Revista de Administração Educacional, Recife, V. 1 . No 1 . 2017 jan./jun. 2017 p. -38- 
Quadro 4 - Objetivos e estratégias definidas a serem desenvolvidas no Plano Estratégico

\begin{tabular}{|c|c|}
\hline Objetivos & Estratégias \\
\hline $\begin{array}{l}\text { Melhorar os processos de Execução Orçamentária } \\
\text { na UFT }\end{array}$ & $\begin{array}{l}\text { Instrumentalizar os processos de execução } \\
\text { orçamentária }\end{array}$ \\
\hline $\begin{array}{l}\text { Construção do Plano de Desenvolvimento } \\
\text { Institucional com os elementos necessários para o } \\
\text { monitoramento das ações }\end{array}$ & $\begin{array}{l}\text { Realizar a construção do PDI conjuntamente com } \\
\text { as Pró Reitoria s afim de instituir os indicadores de } \\
\text { monitoramento das ações do PDI. }\end{array}$ \\
\hline $\begin{array}{llll}\begin{array}{l}\text { Promover } \\
\text { continuado }\end{array} & \text { aperfeiçoamento profissional } \\
\end{array}$ & $\begin{array}{l}\text { Incentivar os servidores na participação de } \\
\text { capacitações oferecidas pela instituição }\end{array}$ \\
\hline $\begin{array}{l}\text { Envolver a todos os servidores da PROAP nas } \\
\text { atividades e objetivos institucionais }\end{array}$ & $\begin{array}{l}\text { Criar um clima de crescimento e realização } \\
\text { pessoal. }\end{array}$ \\
\hline Melhorar o processo de avaliação institucional & $\begin{array}{l}\text { Fortalecer a Comissão Própria de Avaliação e, as } \\
\text { Comissões Setoriais de Avaliação; }\end{array}$ \\
\hline $\begin{array}{l}\text { Criar instrumentos para monitoramento dos } \\
\text { resultados da UFT }\end{array}$ & $\begin{array}{l}\text { Trabalhar com o painel de indicadores da UFT; } \\
\text { Instrumento de acompanhamento dos cursos de } \\
\text { graduação; } \\
\text { Normatizar o programa Gespublica na UFT; }\end{array}$ \\
\hline $\begin{array}{l}\text { Readequar a estrutura organizacional da Pró } \\
\text { Reitoria }\end{array}$ & $\begin{array}{l}\text { Em virtude da recém-criada Pró Reitoria de } \\
\text { Pessoas na universidade desvincular a CAV que } \\
\text { trata somente de avaliação de pessoal e, fazer a } \\
\text { vinculação da Comissão a Nova Pró Reitoria }\end{array}$ \\
\hline $\begin{array}{l}\text { Estabelecer articulação com as demais Pró } \\
\text { Reitoria s da UFT. }\end{array}$ & $\begin{array}{l}\text { Promover reuniões periódicas e estabelecer } \\
\text { projetos de forma integrada }\end{array}$ \\
\hline $\begin{array}{l}\text { Melhoria na Prestação de Contas e na } \\
\text { transparência da Universidade }\end{array}$ & $\begin{array}{l}\text { Buscar apoio junto aos órgãos de controle para } \\
\text { melhor apresentação das contas da Universidade a } \\
\text { sociedade }\end{array}$ \\
\hline $\begin{array}{l}\text { Concluir desenho do Novo Modelo de Gestão da } \\
\text { Pró Reitoria }\end{array}$ & $\begin{array}{l}\text { Fazer a representação gráfica do grande ciclo de } \\
\text { Gestão e os instrumentos a serem utilizados pela } \\
\text { PROAP }\end{array}$ \\
\hline $\begin{array}{l}\text { Buscar mecanismos para a modernização da } \\
\text { Gestão }\end{array}$ & $\begin{array}{l}\text { Estruturar o mapeamento de processos } \\
\text { Estruturar a avaliação e monitoramento dos riscos } \\
\text { da Universidade } \\
\text { Regulamentar procedimentos de atualização e } \\
\text { manutenção da Estrutura Organizacional } \\
\text { Promover a implantação e adequação do SIE } \\
\text { (Sistema de Informações para o Ensino) como } \\
\text { ferramenta de TI voltada para a Gestão } \\
\text { Universitária }\end{array}$ \\
\hline
\end{tabular}

Revista de Administração Educacional, Recife, V. 1 . № 1 . 2017 jan./jun. 2017 p. -38- 
Fonte: Elaboração própria

As etapas que contribuíram para a elaboração do Planejamento Estratégico Situacional da PROAP possibilitaram ao grupo a oportunidade de reflexão sobre os problemas enfrentados pela Pró Reitoria e sobre os aspectos positivos e negativos de sua estrutura, bem como possibilitaram a constatação de algumas oportunidades como, por exemplo, a de pertencer a um universo privilegiado e de excelente conceito no campo educacional brasileiro.

\section{CONSIDERAÇÕES FINAIS}

A Pró Reitoria de Avaliação e Planejamento termina este ciclo com um saldo muito positivo de suas ações, embora algumas delas ainda estejam em fase de implementação. Podese afirmar que um grande passo foi dado com a construção do planejamento estratégico situacional da Pró Reitoria , com reflexos posteriores em toda a universidade.

O planejamento estratégico situacional consistiu na análise sistemática dos pontos fortes e fracos, assim como as ameaças e oportunidades do meio. Com este diagnóstico pudemos estabelecer objetivos, estratégias e ações que permitam uma melhoria na relação entre a instituição e o ambiente em que ela se encontra inserida. Esta ferramenta quando bem elaborada e articulada, propicia condições para o alinhamento do desenvolvimento e a construção do futuro da instituição. Ressalta-se que todo este processo foi construído de forma participativa, de forma a despertar os sentimentos de pertencimentos organizacional e có-responsabilização pela execução das ações e seus processos avaliativos.

A Pró Reitoria de Avaliação e Planejamento é um setor estratégico e articulador dentro da Universidade, tendo assim vários desafios a serem vencidos, mas um caminho foi proposto com a construção de um planejamento estratégico situacional. Agora, é necessário fazer com que este planejamento seja utilizado como ferramenta de gestão e, que as ações a serem realizadas continuem tendo como base os objetivos estabelecidos, utilizando deste instrumento como ferramenta de apoio para suas atividades, que norteie suas ações cotidianas buscando atingir as metas estabelecidas.

Como resultado final, foram definidos a razão de existência de cada diretoria que compõe a estrutura organizacional da Pró Reitoria de Avaliação e Planejamento da Universidade Federal do Tocantins, onde foram definidas as missões de cada diretoria, bem como a missão especifica da PROAP. Este processo culminou com resultados obtidos a partir de técnicas do planejamento estratégico situacional.

Revista de Administração Educacional, Recife, V. 1 . N 1 . 2017 jan./jun. 2017 p. -38- 


\section{REFERÊNCIAS}

ALPERSTEDT, Graziela Dias; MARTIGNAGO, Graciella; FIATES, Gabriela Gonçalves Silveira. O processo de adaptação estratégica de uma instituição de ensino superior sob a ótica da teoria institucional. Revista de Ciências da Administração, v. 8, n. 15, p. 1-24, 2006.

BORGES, Djalma Freire; ARAÚJO, Maria Arlete Duarte de. Uma experiência de planejamento estratégico em universidade: o caso do centro de ciências sociais aplicadas da UFRN. Revista de Administração Pública, v. 35, n. 4, p. 63 a 75, 2001.

ARAÚJO, Maria Arlete Duarte. Planejamento estratégico: um instrumental à disposição das universidades? Revista de administração pública, v. 30, n. 4, p. 74-86, 1996.

LIMA, Jaasiel Nascimento. Planejamento e Orçamento como instrumentos integrados de gestão: o caso da Universidade Federal do Tocantins. Dissertação de mestrado em gestão de políticas públicas. Palmas, 2015.

LOPES, Luiz Antonio Coelho; BERNARDES, F. R. Estruturas administrativas das universidades brasileiras. São Paulo: VIII SEMEAD, 2005.

MARCELINO, Gileno Fernandes. Gestão Estratégica em Universidade: O Caso da Faculdade de Estudos Sociais Aplicados da Universidade de Brasília (FA/UnB). In: Encontro Nacional de Administração (2001). Disponível em: http://www.anpad.org.br/diversos/trabalhos/EnANPAD/enanpad_2003/GPG/2003_GPG313.p df

MATUS, Carlos. Fundamentos da planificação situacional e os métodos do VII Plano da Nação. In: RIVERA, Francisco Javier Uribe. Planejamento e programação em saúde: um enfoque estratégico. São Paulo: Cortez, 1992, cap.3, p.107 - 149.

O plano como aposta. In: Planejamento e Orçamento governamental coletânea volume 1. ENAP, Brasília 1991

Política, Planejamento e Governo. Brasília. Ed. IPEA, Tomos I e II, 1993.

Revista de Administração Educacional, Recife, V. 1 . N 1 . 2017 jan./jun. 2017 p. -38- 